\title{
Coating Metallic Surfaces in Engineering Applications for Improved Performance
}

\author{
Isaac Oamen Festus, Edema Ofuafo Anthony
}

\begin{abstract}
This paper explains the various types of coatings which include metals, polymers, aerogels and ceramics coatings applied on metal surfaces through different methods so as to prevent oxidation, corrosion, cracking, wear and increase surface temperature. Coatings are covering layers applied to metallic surfaces in engineering applications so as to improve performance. They serve as protection to the underlying material. Literatures had it that coating applied in automobile and stationary engines, gas turbines and other internal combustion engines has helped to increase their brake thermal efficiencies. This happened because of increased surface temperature achieved in the combustion chambers due to low thermal conductivity and matched coefficient of thermal expansion of the coating materials.
\end{abstract}

Keywords: Coatings, Performance, Brake Thermal Efficiency, Thermal Conductivity.

\section{INTRODUCTION}

Coatings are defined as covering layers applied to metallic surfaces in engineering applications to mainly reduce heat lost and boost thermal efficiency [1]. These metallic surfaces are found in gas turbines, aero-engines, compression ignition (CI) and spark ignition (SI) engine parts which operate at very high temperatures [1]. The main purpose of coating metallic surfaces in engineering applications is insulating metallic parts from excessive and sustained heat. This gives higher operating temperatures [2]. The major engineering applications where coating is of paramount importance are on the metallic surfaces of compression ignition and spark ignition engine. Coatings are carried out mainly on the cylinder head, piston head, cylinder liner, valves, etc. in the internal combustion engine (ICE) so as to increase combustion temperature and reduce heat lost to cooling systems [2]. The main type of coating applied to engineering components is the ceramic coating. This type of coating has always been regarded as thermal barrier coating (TBC) [2]. Thermal barrier coatings allow flame temperatures which are higher than the melting point of metal in turbines, compression ignition, spark ignition engines and industrial applications [3].

Current thermal barrier coatings are required to reduce heat transfer through the coating [2].

Revised Manuscript Received on April, 182020.

* Correspondence Author

Engr. Isaac Oamen Festus*, Lecturer, Department of Mechanical Engineering, Edo University Iyamho, Uzairue, Edo State. E-mail: isaac.oamen@edouniversity.edu.ng

Engr. Edema Ofuafo Anthony, Lecturer, Department of Mechanical Engineering, Delta State Polytechnic, Otefe-Oghara, Delta State. E-mail: aoedema@gmail.com

(C) The Authors. Published by Blue Eyes Intelligence Engineering and Sciences Publication (BEIESP). This is an open access article under the CC BY-NC-ND license (http://creativecommons.org/licenses/by-nc-nd/4.0/)
They also ensure that engine components are safe from oxidation and hot corrosion [4]-[5]. However, single component coating has been unable to satisfy these multifunctional requirements [3].

In line with the above, a complex thermal barrier coating structure was introduced [7]. Research from the 1970s focused on a preferred coating system comprising three separate layers on the substrate to achieve long-term improvement on control of oxidation and corrosion at elevated temperatures [7]-[3]. The first one is the top coat layer made of ceramic having low thermal conductivity so as to give good thermal insulation for hot engine metallic parts, the second is bond coat layer made of metallic alloy above the substrate which holds the ceramic coat on the substrate, and finally the thin thermally grown oxide (TGO) layer to provide good adherence between the ceramic top coat layer and the bond coat layer [6]. Subjecting the TBC to high temperatures allows the thermally grown oxide (TGO) layer which consists of alumina to protect the substrate from thermal oxidation and corrosion by serving as an oxygen diffusion barrier [4]-[7]. Ceramic coatings applied to internal combustion engines reduce heat which passes from the in-cylinder to engine cooling system [7].

In a normal diesel engine, about 30\% of the total energy is lost to the coolant and research shown that engine coating would be a preferred solution [4]. The main advantages of the engine coating system are improved fuel economy due to low brake specific fuel consumption (BSFC) and improved power output [2]. It also leads to increase in brake thermal efficiency which is mainly based on the temperature inside the combustion [5]. This increase was achieved because of the reduction in heat transfer from the combustion chamber to the piston head during the combustion or expansion stroke [8]. Other advantages are reduced unburned hydrocarbon (UBHC) because at high temperatures and low BSFC, the engine will have sufficient oxygen to combust HC and CO [9]. Thermal barrier coating of piston crown reduces $\mathrm{CO}$ emission when compared with uncoated engine [10]. In ICEs, majority of the heat generated during combustion process is conducted into the piston. This reduces indicated power which then affects the performance of the engines [11]. Engine coating with ceramic thermal barrier improves engine reliability, durability, performance and thermal efficiency [12]-[13].

\section{METHODOLOGY}

In this paper, the method applied is literature review and research on the various types of coatings and the suitable one recommended for improved performance in internal combustion engines where there are many metallic surfaces subjected to high temperatures.

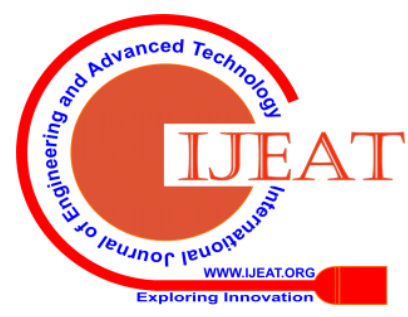




\section{Coating Metallic Surfaces in Engineering Applications for Improved Performance}

\section{A. Types of Coatings}

We have metals, polymers, aerogels and ceramics coatings [14]. These are explained below:

- Metal Coatings: These types of coatings are used in many application areas such as engineering construction, ICEs and provision of electricity [12]. Its benefits are protecting the substrate material from corrosion, providing high temperatures, increasing surface hardness and durability and reducing friction [15]. Metals have high thermal conductivities and as a result hardly act as thermal barrier coatings and therefore not considered for the same applications as ceramics [12]. However, coating them to steel surfaces requires four commonly used methods: hotdip galvanizing, metal spraying, electrochemical deposition and sherardizing [15].

> Hot-Dip Galvanizing: This entails selecting parts of steel and immersing in a bath with molten zinc [16]. This gives metal coating having durability, toughness, corrosionresistant and abrasion-resistant. Hot-dip galvanizing allows metal to pass over degreasing, pickling and flux bath which serves as pre-treatments before it is sent to the zinc bath [14]. The flux solution reinforce zinc coating state into the steel surface. However, the parts to be galvanized is first dried and thereafter immersed in a galvanized bath to make sure that the flux reacts less with the liquid zinc [19]. Hotdip galvanizing is often done at a temperature greater than $450{ }^{0} \mathrm{C}$ and also ensures that the zinc is in a liquid state [14]. To find out if zinc coating would be used as thermal barrier coating, its properties were considered where its hardness was found to be within the range of $185 \mathrm{HV}$ to $301 \mathrm{HV}$ which was greater than steel material used for piston constructions. The disadvantage is low temperature stability [19]. Low temperature galvanized coatings having high concentration of zinc has failed to withstand a temperature increase greater than $225{ }^{0} \mathrm{C}$. Exposing to long period of time at elevated temperatures has caused solid phase transformation in the coatings thereby transforming to an intermetallic iron-zinc phase [11].

$>$ Metal Spraying: This entails the use of zinc, aluminium and more alloys to increase corrosion protection of structural materials that are subjected to aggressive environmental conditions [13]. Here, aluminium serves as a barrier and zinc serves as a sacrificial anode to the metallic surface. Similarly, thermal sprayed metal coating form duplex coating system when over-coated with paints [11]. The mixture of the paint and the metal produces a better protection which then increases the aesthetic value of the component [14]. Using either a gas flame or an electric flame the metal is transformed into molten state which is compressed and projected towards the surface to be coated [11]. Some applications are seen on steel bridges [14].

\footnotetext{
$>$ Electrochemical Deposition: Electrochemical deposition or electroplating is a process that uses electrical current in a liquid medium to produce metal cations which are later deposited on an electrode using an electrolyte medium. This coating process works by considering the principles of a galvanic cell which act in a reverse direction where the rate at which the anode dissolve is the same as the rate at which the cathode is plated. Electrochemical deposition is applied in changing the surface properties of a component and then modifying the abrasion and wear resistance, etc. [12].
}

> Sherardizing: This process allows the coating of metallic components with zinc powder. In this process, the zinc powder evaporates and diffuses into the target forming Zinc-Iron phases [14]. Coatings in this case is between 15 $80 \mu \mathrm{m}$. It is preferred to other zinc because of its great hardness and wear resistance. This makes it possess high capacity to withstand mechanical damage without trading with performance. Common applications is seen in washers, bolts, nuts, springs, castings, etc. [12].

- Polymer Coatings: Polymers compose of repeated monomers forming macromolecules which as a result of its versatility are coated in tough, flexible and adhesive films to safeguard surfaces [3]. Fig. 1 [12] shows the polymerization of polyethylene from ethylene. Polyethylene has become the most common plastic produced nowadays. Polymer coatings are applied in industrial environment due to high tailored production, cost-effectiveness and low thermal conductivities [12]. They have low thermal conductivities as a result of covalent bonding, large molecular size and lack of crystallization. Its uses include corrosion protection and is distinguished in a broad range of applications in tanks, vessels and ducts, cars, coal chutes, legs of oil platforms and packaging [3].

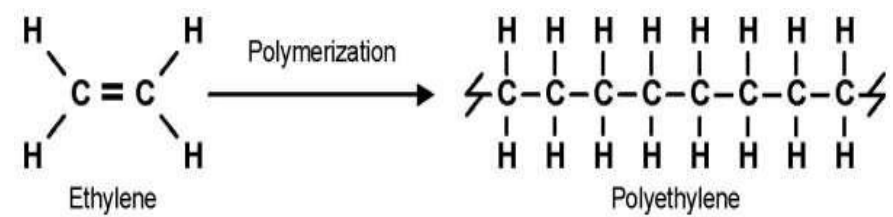

Fig. 1 [12]. Compound formula of polyethylene after polymerization of ethylene

- Aerogel Coatings: In applications requiring high level of thermal insulation, aerogels coatings instead of conventional ceramic coatings are used [16]. Aerogels are synthetic porous ultra-light materials where the liquid in a gel is replaced with a gas that permits very low densities and thermal conductivities [13]. The density and thermal conductivity of silica aerogel monolith is $0.1 \mathrm{~g} / \mathrm{cm}^{3}$ and 15 $\mathrm{mW} / \mathrm{m}^{-1} \mathrm{~K}^{-1}$, respectively.

It is estimated to be 2 - 3 times more insulating per unit thickness than polyurethane foam (PUF) and expanded polystyrene (Styrofoam) [14]. It is a well-known fact that aerogels have not been used in ICE parts especially the piston. Their disadvantages include poor mechanical performance, poor bonding and poor corrosion protection [16].

- Ceramic Coatings: Ceramic coatings are inorganic nonmetallic solid materials defined by crystals, partly crystals or amorphous structure [15]. A number of ceramics are good insulators. Ceramic coatings are good corrosion protection and has the ability to withstand higher temperatures than many other coating materials [14]. Many ceramic coatings have high abrasion resistance thereby making them good candidates for metallic surface coatings in order to extend their lifespan. Coating application in ICEs is mainly done by thermal barrier Coating using ceramics [15]. Investigating the effects of thermal barrier coating using ceramic materials in internal combustion engine performance and exhaust emission behaviors have been carried out by many researchers [15].

Published By:

Blue Eyes Intelligence Engineering 
Investigations on thermal barrier coating in internal combustion engines are mostly focused on diesel engines due to detonation and knocking challenges of spark ignition engines at elevated in-cylinder temperatures [17]. Studies of diesel engines are divided into two main categories: turbocharged and non-turbocharged engines [17]. In nonturbocharged engines, thermal barrier coating of internal combustion engine cylinders generally results in decreased volumetric efficiency [16]. While in turbocharged diesel engines, better performance and exhaust emissions due to improved volumetric efficiency and in-cylinder temperatures are achieved. Exhaust gas energy increase and converted to mechanical energy [17]. Reference [21] reported 30\% decrease in NOx emissions achieved by advance adjustment. 1-30\% reduction in specific fuel consumption [18]. It also reported that specific fuel consumption reduced by $1-2 \%$. Reference [21] reported specific fuel consumption decrease between the ranges of $16-37 \%$ using ceramic thermal barrier coating. Similarly, [22] and [23] observed $8 \%$ increase in the specific fuel consumption making use of the ceramic thermal barrier coating. In the same vein, [19] specified that thermal barrier coating resulted in $10 \%$ increase in specific fuel consumption. Studies showed that thermal barrier coating using ceramic materials reduce heat lost from cylinders to engine block and cooling system between 5-70\%. Reference [24] reported between 49.2-66.5\% of heat rejection rate after applying ceramic coating.

\section{RESULT AND DISCUSSION}

There are no experimental or design results for this research. Hence, discussion is not possible.

\section{CONCLUSION} applications on metallic surfaces including the detailed explanation of the different types of coatings, one can conclude that coating is very important in internal combustion engines (ICEs) where high brake thermal efficiency is required to improve the engine performance. Hence, ceramic coatings is recommended for ICE's application. Moreover, coating a metallic surface also means insulating it from excessive heat lost.

\section{REFERENCES}

1. B. Ekrem. "Thermal analysis of functionally graded coating Al-Si alloy and steel pistons." Journal of Energy Conversion and Management, vol. 202(16), 2008, pp. 325-336.

2. S. Molla, and G. Shankariah. "Design and analysis of the piston using composite materials." International Journal of Innovative Research in Science, Engineering and Technology, vol. 6(8), 2017, pp. 368-373.

3. T. Hejwowski, and A. Weronsk. "The effects of thermal barrier coating on diesel engine performance." Journal of Vacuum Surface Engineering, vol. 65, 2002, pp. 427-432.

4. J. I. Ramos. Internal Combustion Engine Modeling, $2^{\text {nd }}$ ed. USA: Taylor \& Francis, 1989, p. 278.

5. J. B. Heywood. Internal Combustion Engine Fundamentals, International ed. USA: McGraw-Hill Book Company, 1998, pp. 930.

6. P. M. Pierz. "Thermal barrier coating development for diesel engine aluminum pistons." Surface \& Coating Technology, vol. 61(1), 1993, pp. 60-66.

7. R. Kamo, D. Assanis, and W. Bryzik. "Thin thermal barrier coatings for engines." SAE, USA, 1989, pp. 48-60.

8. D. Balaji, and T. Maridurai. "Experimental investigation of engine performance and emission in diesel engine by aluminium-titanium thermal barrier coating." International Journal of Chemical Science, vol. 14(1), 2016, pp. 152-160.
Having defined coatings and their engineering

9. P. M. Neil, P. B. Praveen, and V. Nitin. "Thermal analysis of ceramic coated aluminum piston used in CI engine using ANSYS." International Journal of Advance Engineering and Research Development, vol. 4(12), 2017, pp. 137-144.

10. S. Dhileepan, V. Gnanamoorthi, and M. N. Marudhan. "Performance and emission characteristics of thermal barrier coating on piston crown in diesel engine.” International Journal of Latest Engineering Research and Applications (IJLERA), vol. 1(9), 2016, pp. 11-16.

11. Ganesan, V. (2007). Internal Combustion Engines, $3^{\text {rd }}$ ed. New Delhi: Tata McGraw-Hill Publishing Company Ltd, 645 pp.

12. R. F. Colin, and T. K. Allan, Internal Combustion Engines Applied Thermosciences, $3^{\text {rd }}$ ed. UK: John Wiley \& Sons Ltd, 2016, p. 477.

13. E. Büyükkaya, "Ceramic coating application and performance analysis in a diesel engine." Unpublished Msc Thesis. Istanbul Technical University,Turkey, 1994, p. 80.

14. B. Ekrem, and C. Muhammet, "Thermal analysis of a ceramic coating diesel engine piston using 3-D finite element method (FEM)." Journal of Surface and Coatings Technology, vol. 202, 2007, pp. 398-402.

15. M. G. Hocking, V. Vasatasree, and P. S. Sidky, Metallic and Ceramic Coatings, High Temperature and Applications, London. UK, 1989, p. 213.

16. R. Kamo, W. Bryzik, M. Reid, and M. Woods, Coatings for Improving Engine Performance, 1997 International \& Congress and Exposition, Detroit, Michigan, USA, 1997, pp. 49-60.

17. A. Parlak, Experimental Investigation of Injection Advance and Compression Ratio of a Supercharged Ceramic Coated Diesel Engine. Unpublished PhD Thesis, Sakarya University, Turkey (in Turkish), 2000, p. 87.

18. Y. Miyairi, T. Matsumsa, T. Ozawa, H. Odcawa, and N. Nakashima, "Selective heat insulation of combustion chamber wall, for a diesel engine with monolithic ceramics." SAE Technical Paper, vol. 89(01), 1989, p. 41.

19. S. Kimura, Y. Matsui, and T. Ltoh, Effects of Combustion Chamber Insulation on the Heat Rejection and Thermal Efficiency of Diesel Engines, 1992 International \& Congress and Exposition, Detroit, Michigan, USA, 1992, pp. 24-28.

20. N. Hay, P. M. Watt, M. J. Ormerod, G. P. Burnett, P. W. Beesley, and B. A. French, "Design study for a low heat loss version of the dover engine." Proceedings of the Institution of Mechanical Engineers, vol. 200, 1986, pp. 24-30.

21. P. Ramaswamy, S. Seetharamu, K. B. R. Varma, N. Raman, and K. J. Rao, "Thermomechanical fatigue characterization of zirconia (8\% $\mathrm{Y}_{2} \mathrm{O}_{3}-\mathrm{ZrO}_{2}$ ) and mullite thermal barrier coatings on diesel engine components: effect of coatings on engine performance." Proceedings of the Institution of Mechanical Engineers, vol. 214, 2000, pp. 729742 .

22. X. Sun, W. G. Wang, D. W. Lyons, and X. Gao, Experimental Analysis and Performance Improvement of a Single Cylinder Direct Injection Turbocharged Low Heat Rejection Engine, 1993 International \& Congress and Exposition, Detroit, Michigan, 1993, pp. 45-69.

23. R. A. Beg, P. K. Bose, B. B. Ghosh, T. K. Banerjee, and A. K. Ghosh, Experimental Investigation on Some Performance Parameters of a Diesel Engine using Ceramic Coating on the Top of the Piston, 1997 International Congress \& Exposition, Detroit, Michigan, USA, 1997, pp. 158-163.

24. Y. Rasihhan, and F. J. Wallace, (1991). "Piston-liner thermal resistance model for diesel engine simulation." Proceedings of the Institution of Mechanical Engineers, vol. 205, 1991, pp. 34-39.

\section{AUTHORS' PROFILE}

Engr. Isaac Oamen Festus holds B.Eng (Mechanical Engineering) and M.Eng (Thermo-Fluids/Thermal Power Engineering) from the Ambrose Alli University, Ekpoma Edo State, Nigeria in 2003 and 2008, respectively. He is presently doing his $\mathrm{PhD}$ in the same University. He works as a lecturer in the Department of Mechanical Engineering, Faculty of Engineering in Edo University Iyamho located in Uzairue, Edo State. He has over 40 publications and his research interest includes thermal and structural analyses, finite element analysis, 2D and 3D modelling in SolidWorks, AutoCAD and ANSYS softwares, computational fluid dynamics and analysis of internal combustion engines.

Published By:

Blue Eyes Intelligence Engineering

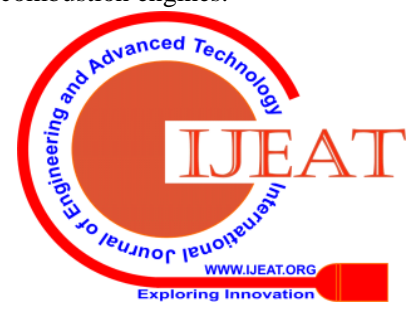




\section{Coating Metallic Surfaces in Engineering Applications for Improved Performance}

He is a member of Nigerian Society of Engineers and a registered engineer with the Council for the Regulation of Engineering in Nigeria. His email address is isaac.oamen@edouniversity.edu.ng and mobile phone number as 08037758993.

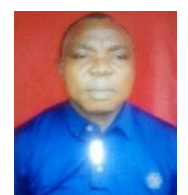

Engr. Edema Ofuafo Anthony holds B.Sc (Mechanical Engineering) and M.Tech (Mechanical Engineering) from the University of Lagos, Lagos State and University of Science and Technology, Port-Harcourt, Rivers State, respectively. He works as a lecturer in the Department of Mechanical Engineering, Delta State Polytechnic, Otefe-Oghara, Delta State. He is a member of Nigerian Society of Engineers and a registered engineer with the Council for the Regulation of Engineering in Nigeria. His email address is aoedema@gmail.com and mobile phone number as 08063347795.

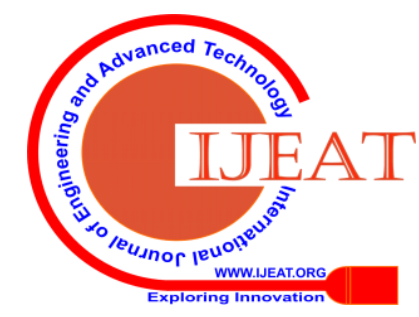

